\title{
Psychological Aspects of Binge Eating Disorder (ACT)
}

\author{
José Guedes da Silva Júnior* \\ Department of Biochemistry, Federal University of Pernambuco, Brazil
}

*Corresponding author: José Guedes da Silva Júnior, Center for BiosciencesDepartment of Biochemistry, Federal University of Pernambuco, Avenida Prof. Moraes Rego, 1235, Cidade Universitária, Recife-PE 50.670-501, Brazil.

\author{
Received Date: February 11, 2020
}

Published Date: February 26, 2020

\section{Perspective}

The studies that integrated the development of this research were carried out between the years 2015 and 2019, where the descriptors "psychology", "compulsion", "eating" and "feelings" were used, whereas the database used was Google Scholar. As inclusion criteria, scientific articles published in Portuguese were selected, which are in accordance with the descriptors and years previously cited, as exclusion criteria, articles published before the year 2015 and written in a foreign language.

According to Barbosa et al. [1], eating disorders such as bul nervous imia, anorexia nervosa, rumination disorder, binge eating disorder and others, affect most young people, predominantly female adolescents. However, these data may not reflect the current reality, as they are only the most serious cases that reach medical knowledge. According to their research, the authors state that through a qualitative and quantitative analysis of the scientific knowledge produced by psychology professionals on the subject, there was a lack in the development of new research, considering that the disorder in question can trigger various psychopathological symptoms that will imply the health of individuals.

Due to the great need of young people to feel inserted in the social standards of beauty, especially the group formed by female adolescents, the emergence of psychopathologies becomes something common. When looking for ways to bring them closer to better physical and social conditions, such as having a body with a low percentage of fat and achieving visibility in different groups, theseyoung women are subjected to rigid and uncontrolled diets that have implications for their physical well-being and psychological. In addition, adolescents who do not fit the standards of beauty can develop compulsive disorders caused by psychological suffering when they do not feel included in the social media they desire.
The studies are to Bolognese et al. [2] about adolescents and binge eating disorder, expose that cognitive and behavioral factors associated with the environment can help a better understanding of the reasons why body image distortions may be present eating disorders. The authors mentioned above (Apud Almeida; Loureiro; Santos, 2002) still report that these subjects manifest psychosocial changes due to the fact that they present insecurity, anxiety and greater difficulty in adapting to the environment. Thus, emphasize the importance of care and attention promoted by teams of multidisciplinary interventions to these subjects.

According to Fortes et al. [3], risky behaviors towards eating for individuals with eating disorders are related to mood. In view of the growing number of individuals with binge eating disorder (ACT), Cauduro, Paz, Pacheco [4] investigated the psychological assessment instruments that are most used for the descriptive analysis of the condition, where they highlighted four instruments: the Eating Disorder Examination (EDE), the Beck Depression Inventory (BDI), the Structured Clinical Interview for the DSM (SCID) and the Rosenberg Self- Esteem Scale (RSE). These instruments allow a more focused analysis regarding the psychological aspects associated with ACT, including comorbidities, and can validate the presence of the disorder.

Another important factor is the effectiveness of cognitivebehavioral therapy (CBT) for the treatment of psychological aspects associated with the disorder in question, as this approach seeks to intervene about automatic thoughts, intermediate beliefs, central belief, cognitive distortions and others, presenting significant results by interfering in both $\mathrm{n}$ cognitive factors such as the behavioral factors that cause mental health problems (Cauduro; Peace; Pacheco, [4]. 
Moreira et al. [5] conducted a survey about the body image distortions present in a person with an eating disorder and claim that these distortions are common, especially in cases of anorexia nervosa. The authors emphasize the importance of acquiring knowledge and discussing eating disorders, specifically anorexia and bulimia nervosa, considering that many students and nutrition professionals report severe cases of both disorders.

When referring to the feelings present in people with ACT, the American Psychiatric Association [6] describes the frequency of feelings as shame, disgust and guilt. The authors D'A ugustin, Pinho and Falcone [7] affirm the existence of the relationship between anger and dysfunctional eating behavior. Corroborating with the previous idea, the authors describe that binge eating assumes the function of relieving the discomfort caused by anger, thus being characterized as a negative reinforcement. By decreasing anger, compulsion is configured as the first solution option for people with ACT. For this reason, it develops the following cycle: situaçõ interpersonal es negative, anger and constant episodes of binge eating.

Ferreira [8] discusses about the binge generate the subject a variety of aversive mood states. According to data presented by the author, we find but anger, the guilt, the grief and fear. In addition, she says that some of the triggers that influence interpersonal stress factors are negative feelings that are related to body weight and body shape.

During studies on the relationship between sexual abuse and eating disorders Rocha, Andrade and Silva [9] understood that the abused body can trigger some eating disorder. This is due to the body recording the entire life experience and seeking to relate to the world according to the sequels of certain experiences. Thus, people who have suffered sexual abuse show low self-esteem and do not accept their own bodies because they carry the stress caused by the abuse. Thus, because they understand that their curves provide violence, they begin to use pathological eating practices as a means of modifying the body, adhering to exaggerated thinness or excess weight.

An important characteristic when working on psychological aspects in binge eating disorder are the functions of the hypothalamus, as the hypothalamus is related to food satiety and the states of emotions and mood, in addition to being responsible for sensations related to sexual pleasure that it can be compared to "feeling good" after a meal [10].

Florido et al. [11] developed a research about behavioral and dietary strategies to fight obesity, in this research the authors stated that patients with binge eating disorder show a higher rate of failure in weight loss in the long term, being essential psychological monitoring of these individuals. Subjects with ACT have more severe levels of depression and obsessive-compulsive symptoms, with which strong feelings of inadequacy and inferiority arise.

Intervening positively with this population group leads to better living conditions and, consequently, a decrease in other disorders and psychological problems. It is worth noting that when reviewing the literature with the topic addressed, it was observed that most studies are linked to eating disorders in adolescents. With this, the greater number of scientific productions becomes essential for the improvement of the cognitions of these subjects to occur and, primarily, in the reduction of the implications caused throughout their lives. Developing activities that aim to improve health professionals such as nutritionists, doctors, physical education professionals and psychologists, is essential to reduce cases of ACT.

\section{Acknowledgement}

None.

\section{Conflict of Interest}

No conflict of interest.

\section{References}

1. BARBOSA, Aline LP (2019) Psychology and Eating Disorders: Scientific Production on Anorexia and Bulimia Nervosa, p. 1-15.

2. Bolognese, Marciele Binge (2018) Eating disorder: associated factors in overweight and obese adolescents. Psychology Health \& Diseases 19(3): 755-763.

3. FORTES, Leonardo de Sousa (2016) Relationship between mood and risky eating behaviors for eating disorders in adolescents. Brazilian Journal of Psychiatry.

4. Cauduro, Giovanna Nunes, PACHECO, Janaína Thaís Barbosa, PAZ Gabriel Machado (2018) Assessment and intervention in binge eating disorder (tca): a systematic review. Psycho 49(4): 384-394.

5. MOREIRA, Daiane Evangelho (2017) Eating disorders, body image perception and nutritional status: a comparative study among Nutrition and Administration students. Magazine of the Brazilian Nutrition Association-RASBRAN 8(1): 18-25.

6. American Psychiatric Association (2014) DSM-5: Diagnostic and statistical manual of mental disorders. Artmed Editora.

7. D’AUGUSTIN, Juliana Furtado, PINHO, Vanessa Dordron de, FALCONE, Eliane Mary de Oliveira (2017) Evaluation of anger and social skills in eating disorders. Brazilian Journal of Cognitive Therapies 13(2): 113121.

8. Ferreira Talita Dantas T (2018) Food ranstornos: main symptoms and psychological characteristics. REVISTA UNINGÁ 55(2): 169-176.

9. Da Rocha, Denise Brito ANDRADE, Angela Cardoso, DA SILVA, Carlos Antônio Bruno (2018) Lives crossed by sexual abuse and eating disorder. CIAIQ 2.

10. PEREIRA, Filomena Maria Coutinho (2016) Periodic binge eating and sexual satisfaction. 2016. 155 f. Dissertation (Master in Metabolic Diseases and Eating Behavior) - Faculty of Medicine, University of Lisbon, Lisbon.

11. FLORIDO, Lucas Moreira (2019) Combate obesity: behavioral and dietary strategies. Cadernos da Medicina-UNIFESO 2(2). 